\title{
p70 S6 kinase negatively regulates fibroblast growth factor 2-stimulated interleukin-6 synthesis in osteoblasts: function at a point downstream from protein kinase $C$
}

\author{
S Takai ${ }^{1}$, Y Hanai ${ }^{1,2}$, R Matsushima-Nishiwaki ${ }^{1}$, C Minamitani ${ }^{1,3}$, T Otsuka ${ }^{3}$, H Tokuda ${ }^{1,2}$ and O Kozawa ${ }^{1}$ \\ ${ }^{1}$ Department of Pharmacology, Gifu University Graduate School of Medicine, Gifu 501-1194, Japan \\ ${ }^{2}$ Department of Clinical Laboratory, National Center for Geriatrics and Gerontology, National Hospital for Geriatric Medicine, Obu 474-8511, Japan \\ ${ }^{3}$ Department of Orthopedic Surgery, Nagoya City University Graduate School of Medical Sciences, Nagoya 467-8601, Japan \\ (Correspondence should be addressed to O Kozawa; Email: okozawa@gifu-u.ac.jp)
}

\begin{abstract}
We have previously reported that protein kinase C negatively regulates basic fibroblast growth factor (FGF-2)-stimulated synthesis of interleukin-6 (IL-6), a potent bone resorptive agent, in osteoblast-like MC3T3-E1 cells. To further clarify the mechanism underlying the synthesis of IL-6 in osteoblasts, we investigated whether p70 S6 kinase is involved in the FGF-2stimulated IL-6 synthesis in these cells. Rapamycin, an inhibitor of p70 S6 kinase, significantly enhanced the FGF-2-stimulated IL-6 synthesis in a dose-dependent manner. Downregulation of p70 S6 kinase by siRNA markedly amplified the FGF-2stimulated IL-6 synthesis. 12-O-Tetradecanoylphorbol-
\end{abstract}

13-acetate (TPA), a direct activator of protein kinase $\mathrm{C}$, induced the phosphorylation of p70 S6 kinase. Go6976 and bisindolylmaleimide I, inhibitors of protein kinase $\mathrm{C}$, suppressed the TPA-stimulated phosphorylation of p70 S6 kinase. Additionally, protein kinase $\mathrm{C}$ inhibitors markedly reduced the phosphorylation of p70 S6 kinase induced by FGF-2. These results strongly suggest that p70 S6 kinase functions at a point downstream of protein kinase $\mathrm{C}$ and limits the FGF-2-stimulated IL-6 synthesis in osteoblasts.

Journal of Endocrinology (2008) 197, 131-137

\section{Introduction}

Interleukin-6 (IL-6), which is a multifunctional cytokine that has important physiological effects on a wide range of functions such as promoting B-cell differentiation, T-cell activation, and inducing acute phase proteins (Akira et al. 1993, Heymann \& Rousselle 2000, Kwan et al. 2004), is one of the most potent osteoclastogenic factors (Ishimi et al. 1990, Roodman 1992, Akira et al. 1993, Kwan et al. 2004). Bone metabolism is strictly regulated by two functional cells, osteoblasts and osteoclasts, responsible for bone formation and bone resorption respectively (Nijweide et al. 1986). Bone resorption may be enhanced by the increased local production of inflammatory cytokines such as tumor necrosis factor- $\alpha$ and interleukin-1. In osteoblasts (Helle et al. 1988, Ishimi et al. 1990, Littlewood et al. 1991), it has been reported that bone resorptive agents such as tumor necrosis factor- $\alpha$ and interleukin- 1 stimulate the synthesis of IL-6. Thus, accumulating evidence indicates that IL-6 secreted from osteoblasts plays a crucial role as a downstream effector of bone resorptive agents.

Osteoblasts synthesize basic fibroblast growth factor (FGF-2), and FGF-2 is embedded in bone matrix (Baylink et al. 1993, Hurley et al. 1993). It is well known that FGF-2 expression in osteoblasts is detected during fracture repair (Bolander 1992).
Therefore, there is no doubt that FGF-2 plays a crucial role in fracture healing, bone remodeling, and osteogenesis (Marie 2003). We have previously reported that FGF-2 autophosphorylates FGF receptors 1 and 2 among four structurally related high-affinity receptors in osteoblast-like MC3T3-E1 cells (Suzuki et al. 1996). As for IL-6 synthesis in osteoblasts, we have shown that FGF-2 induces IL-6 synthesis in osteoblasts (Kozawa et al. 1997a). In addition, we have reported that FGF-2 induces IL-6 synthesis via the activation of $\mathrm{p} 38$ MAPK, but also limits the over-synthesis of IL-6 via the activation of protein kinase C pathways (Kozawa et al. 1997a, 1999). However, the exact mechanism underlying the IL-6 synthesis in osteoblasts remains to be clarified.

It is well recognized that p70 S6 kinase is a mitogenactivated serine/threonine kinase, which is required for cell proliferation and G1 cell cycle progression (Pullen \& Thomas 1997). In osteoblasts, it has been shown that fluoroaluminate upregulates p70 S6 kinase phosphorylation (Susa et al. 1997). We have previously reported that p70 S6 kinase plays a role as a negative regulator in platelet-derived growth factor BB-stimulated synthesis of IL-6 in osteoblast-like MC3T3E1 cells (Takai et al. 2007a). With regard to FGF-2 effect on osteoblasts, we recently demonstrated that FGF-2 induces the activation of p70 S6 kinase in osteoblast-like MC3T3-E1 
cells, and the activated p70 S6 kinase plays an inhibitory role in the FGF-2-stimulated release of vascular endothelial growth factor (VEGF) through upregulation of stressactivated protein kinase/c-Jun N-terminal kinase, composing a negative feedback loop, in osteoblasts (Takai et al. 2007b). However, the exact role of p70 S6 kinase in osteoblasts has not yet been fully elucidated.

In the present study, we investigated whether p70 S6 kinase is involved in the FGF-2-stimulated IL-6 synthesis in osteoblast-like MC3T3-E1 cells. We here show that p70 S6 kinase activated by FGF-2 negatively regulates IL-6 synthesis at a point downstream from protein kinase $\mathrm{C}$ in these cells.

\section{Materials and Methods}

\section{Materials}

Recombinant human FGF-2 and mouse IL-6 enzyme immunoassay (ELISA) kit was purchased from R\&D Systems Inc. (Minneapolis, MN, USA). Rapamycin, bisindolylmaleimide I, Go6976, and calphostin C were obtained from Calbiochem-Novabiochem Co. (La Jolla, CA, USA). 12-OTetradecanoylphorbol-13-acetate (TPA) was purchased from Sigma Chemical Co. Phospho-specific p70 S6 kinase antibodies were purchased from Cell Signaling Inc. (Beverly, MA, USA). Enhanced chemiluminescence (ECL) Western Blotting Detection System was purchased from Amersham Biosciences. Control short interfering RNA (siRNA; Silencer Negative Control no. 1 siRNA) or p70 S6 kinase siRNA (Silencer Predesigned siRNA, siRNA ID no. 75849, 75755, and 75942) was purchased from Ambion (Austin, TX, USA). siLentFect was purchased from Bio-Rad. Other materials and chemicals were obtained from commercial sources. Rapamycin, TPA, bisindolylmaleimide I, Go6976, and calphostin C were dissolved in dimethyl sulfoxide. The maximum concentration of dimethyl sulfoxide was $0 \cdot 1 \%$, which did not affect the assay for IL-6 or western blot analysis.

\section{Cell culture}

Cloned osteoblast-like MC3T3-E1 cells derived from newborn mouse calvaria (Sudo et al. 1993) were maintained as described previously (Kozawa et al. 1997b). Briefly, the cells were cultured in $\alpha$-minimum essential medium $(\alpha$-MEM) containing $10 \%$ fetal calf serum (FCS) at $37^{\circ} \mathrm{C}$ in a humidified atmosphere of $5 \% \mathrm{CO}_{2} / 95 \%$ air. The cells were seeded onto $35 \mathrm{~mm}\left(5 \times 10^{4}\right)$ or $90 \mathrm{~mm}\left(5 \times 10^{5}\right)$ diameter dishes in $\alpha$-MEM containing $10 \%$ FCS. After 5 days, the medium was exchanged for $\alpha$-MEM containing $0 \cdot 3 \%$ FCS. The cells were used for experiments after $48 \mathrm{~h}$. Primary cultured osteoblasts were obtained from the calvaria of newborn (1 or 2 days old) balb/c mice as described previously (Yoshida et al. 2004). The cells were seeded onto $90 \mathrm{~mm}$ diameter dishes $\left(25 \times 10^{4}\right.$ cells $)$ in $\alpha$-MEM containing $10 \%$ FCS. The medium was changed every 3 days until the cells reached confluence. Then, the medium was exchanged for $\alpha$-MEM containing $0 \cdot 3 \%$ FCS. The cells were used for experiments after $48 \mathrm{~h}$.

\section{IL-6 assay}

The cultured cells were stimulated by various doses of FGF-2 in $1 \mathrm{ml} \alpha$-MEM containing $0 \cdot 3 \%$ FCS for the indicated periods. When indicated, the cells were pretreated with rapamycin for $60 \mathrm{~min}$. The conditioned medium was collected at the end of the incubation, and the IL-6 concentration was measured by ELISA kit according to the manufacturer's instruction. The assay kit can detect the mouse IL-6 in the range between $7 \cdot 8$ and $250 \mathrm{pg} / \mathrm{ml}$. When the samples generate values greater than $250 \mathrm{pg} / \mathrm{ml}$, the samples were adequately diluted with calibrator diluent provided with the kit and re-assayed. The absorbance of ELISA samples was measured at $450 \mathrm{~nm}$ with EL 340 Bio Kinetic Reader (Bio-Tek Instruments Inc., Winooski, VT, USA).

\section{Short interfering $R N A$ transfection}

To knock down p70 S6 kinase in MC3T3-E1 cells, the cells were transfected with control siRNA (Silencer Negative Control no. 1 siRNA) or p70 S6 kinase siRNA (Silencer Predesigned siRNA, siRNA ID no. 75849, 75755, and 75942, Ambion) using the siLentFect (Bio-Rad) according to the manufacturer's protocol. In brief, the cells were seeded onto $35 \mathrm{~mm}\left(1 \times 10^{5}\right)$ diameter dish in $\alpha$-MEM containing $10 \%$ FCS and subcultured for $48 \mathrm{~h}$. After that, the cells were incubated at $37^{\circ} \mathrm{C}$ for $48 \mathrm{~h}$ with $250 \mathrm{nM}$ siRNA-siLentFect complexes. As a result, we confirmed that siRNA ID no. 75849 had a most prominent effect to silence the p70 S6 kinase among these three siRNAs. The siRNA ID no. 75849 caused $\sim 80 \%$ reduction in the p70 S6 kinase levels compared with those of control siRNA (Takai et al. 2007b). Then, we used siRNA ID no. 75849 in the experiment of the effect of $\mathrm{p} 70 \mathrm{~S} 6$ kinase downregulation on the FGF-2 stimulated IL-6 synthesis.

\section{Western blot analysis}

The cultured cells were stimulated by TPA or FGF-2 in $\boldsymbol{\alpha}$-MEM containing $0 \cdot 3 \%$ FCS for the indicated periods. When indicated, the cells were pretreated with bisindolylmaleimide I, Go6976, and calphostin C for $60 \mathrm{~min}$. The cells were washed twice with PBS and then lysed, homogenized, and sonicated in a lysis buffer containing $62.5 \mathrm{mM}$ Tris- $\mathrm{HCl}$ (pH 6.8), 2\% SDS, $50 \mathrm{mM}$ dithiothreitol, and 10\% glycerol. The cytosolic fraction was collected as a supernatant after centrifugation at $125000 \mathrm{~g}$ for $10 \mathrm{~min}$ at $4{ }^{\circ} \mathrm{C}$. SDS-PAGE was performed according to Laemmli (1970) in $10 \%$ polyacrylamide gel. Western blot analysis was performed as described previously (Kato et al. 1996) using phospho-specific p70 S6 kinase antibodies and p70 S6 kinase antibodies, with peroxidase-labeled antibodies raised in goat against rabbit IgG being used as secondary antibodies. Peroxidase activity on the 

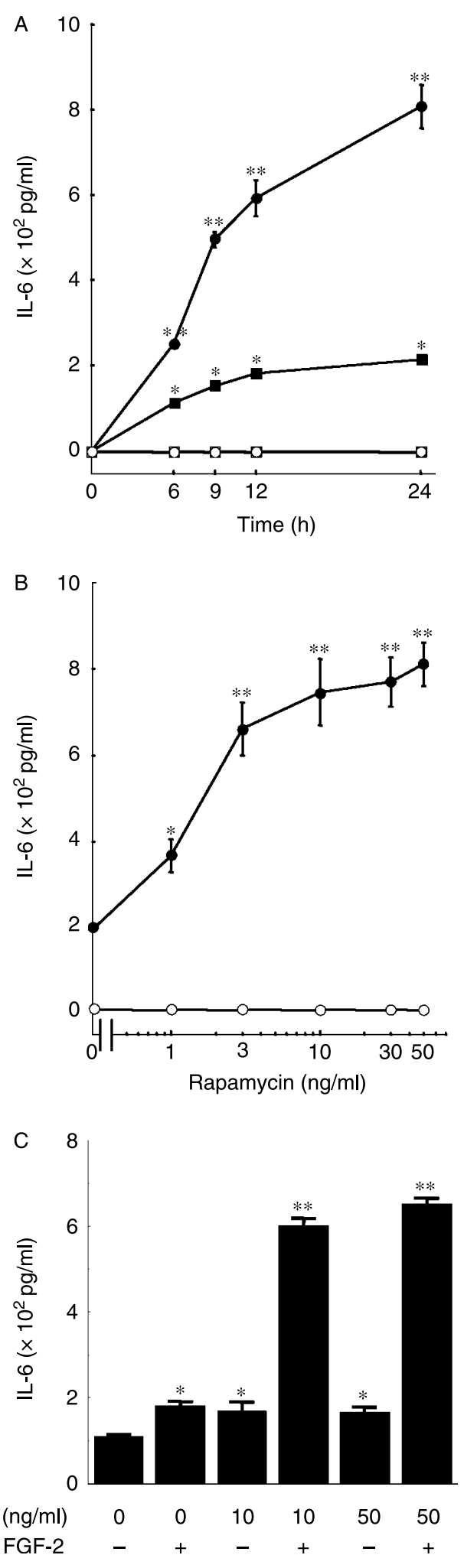

www.endocrinology-journals.org polyvinylidene fluoride (PVDF) sheet was visualized on X-ray film by means of the ECL Western Blotting Detection System. The densitometric analysis was performed using Molecular Analyst/Macintosh (Bio-Rad Laboratories).

\section{Statistical analysis}

The data were analyzed by ANOVA followed by the Bonferroni method for multiple comparisons between pairs, and $P<0 \cdot 05$ was considered significant. All data are presented as the mean + S.E.M. of triplicate determinations from three independent cell preparations. Each experiment was repeated three times with similar results.

\section{Results}

Effect of rapamycin on the FGF-2-stimulated IL-6 synthesis in MC3T3-E1 cells

We have previously shown that FGF-2 induces the activation of p70 S6 kinase in osteoblast-like MC3T3-E1 cells (Takai et al. $2007 b$ ). In addition, we have also previously reported that the levels of phosphorylated p70 S6 kinase reached its peak at 45 minutes after the stimulation of FGF-2 and decreased thereafter (Takai et al. 2007b). In order to clarify the involvement of p70 S6 kinase in the FGF-2-induced synthesis of IL-6 in MC3T3-E1 cells or not, we examined the effect of rapamycin, a specific inhibitor of p70 S6 kinase (Kuo et al. 1992, Price et al. 1992), on the FGF-2-stimulated synthesis of IL-6. We have previously showed that FGF-2 induces IL-6 synthesis by MC3T3-E1 cells in a time-dependent manner (Kozawa et al. 1997a). Rapamycin, which had no effect on the basal levels of IL-6, significantly amplified the FGF-2-induced synthesis of IL-6 in a time-dependent manner. The amplifying effect of rapamycin was observed at least $6 \mathrm{~h}$ after FGF-2 stimulation (Fig. 1A). In addition, the amplifying effect of rapamycin was dose dependent in the range between 1 and $50 \mathrm{ng} / \mathrm{ml}$ (Fig. 1B). Rapamycin at $50 \mathrm{ng} / \mathrm{ml}$ caused $\sim 300 \%$ enhancement in the FGF-2 effect. We next examined the effect of rapamycin

Figure 1 Effect of rapamycin on the FGF-2-stimulated IL- 6 synthesis in osteoblasts. (A) Osteoblast-like MC3T3-E1 cells were pretreated with $10 \mathrm{ng} / \mathrm{ml}$ rapamycin (circles) or vehicle (squares) for $60 \mathrm{~min}$, and then stimulated by $70 \mathrm{ng} / \mathrm{ml} \mathrm{FGF-2} \mathrm{(solid} \mathrm{symbols)} \mathrm{or} \mathrm{vehicle} \mathrm{(open}$ symbols) for the indicated periods. ${ }^{*} P<0 \cdot 0005$, compared with the control. ${ }^{* *} P<0 \cdot 0005$, compared with the value of FGF-2 alone.

(B) Osteoblast-like MC3T3-E1 cells were pretreated with various doses of rapamycin for $60 \mathrm{~min}$, and then stimulated by $70 \mathrm{ng} / \mathrm{ml} \mathrm{FGF-2}$

(O) or vehicle $(O)$ for $24 \mathrm{~h}$. ${ }^{*} P<0 \cdot 001$, compared with the value of FGF-2 alone. ${ }^{* * P} P<0 \cdot 0005$, compared with the value of FGF-2 alone. (C) Primary culture of osteoblasts was pretreated with various doses of rapamycin for $60 \mathrm{~min}$, and then stimulated by $70 \mathrm{ng} / \mathrm{ml}$ FGF-2 or vehicle for $24 \mathrm{~h} .{ }^{*} P<0 \cdot 01$, compared with value of the control. ${ }^{* *} P<0 \cdot 005$, compared with the value of FGF-2 alone. (A-C) Each value represents the mean \pm S.E.M. of triplicate determinations from three independent cell preparations. Similar results were obtained with two additional experiments. 
in primary cultured mouse osteoblasts. We found that FGF-2 significantly induced IL-6 synthesis also in these osteoblasts. In addition, rapamycin significantly increased the FGF-2-stimulated IL-6 synthesis in the range between 10 and $50 \mathrm{ng} / \mathrm{ml}$ (Fig. 1C).

Effect of $p 70$ S6 kinase down regulation on the

FGF-2-stimulated IL-6 synthesis in MC3T3-E1 cells

To further confirm the enhancement by rapamycin of IL-6 synthesis, we examined the effect of p70 S6 kinase downregulation by $\mathrm{p} 70$ S6 kinase siRNA on the IL-6 synthesis induced by FGF-2 in osteoblast-like MC3T3-E1 cells. We previously found that p70 S6 kinase siRNA (250 nM) caused $\sim 80 \%$ reduction in the p70 S6 kinase levels compared with those of control siRNA (Takai et al. 2007b). In the p70 S6 kinase downregulated cells, the basal levels of IL-6 were upregulated while the levels of IL-6 were undetectable in the control siRNA-transfected cells (Fig. 2). The FGF-2induced levels of IL-6 synthesis in p70 S6 kinase downregulated cells were markedly enhanced compared with those in the control cells. Downregulation of p70 S6 kinase caused approximately ten times enhancement in the FGF-2 effect (Fig. 2).

Effect of TPA on the phosphorylation of p 70 S6 kinase in MC3T3-E1 cells

In our previous studies (Suzuki et al. 1996, Kozawa et al. 1997a), we have reported that FGF-2 stimulates the activation of protein kinase $\mathrm{C}$ through hydrolysis of phospholipase C-induced

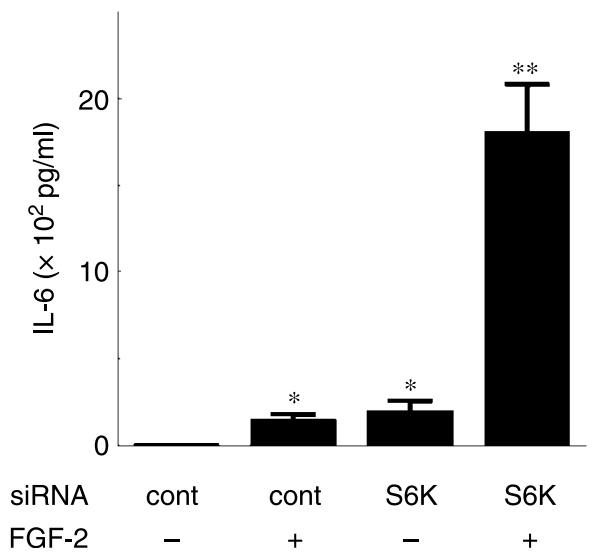

Figure 2 Effect of p70 S6 kinase (S6K) siRNA on the FGF-2stimulated IL-6 synthesis in MC3T3-E1 cells. The cultured cells were transfected with control siRNA (cont) or p70 S6 kinase siRNA (siRNA ID no. 75849, Ambion; S6K) using the siLentFect according to the manufacturer's protocol. The cells were stimulated by $70 \mathrm{ng} / \mathrm{ml} \mathrm{FGF-2} \mathrm{or} \mathrm{vehicle} \mathrm{for} 9 \mathrm{~h}$. Each value represents the mean + s.E.M. of triplicate determinations from three independent cell preparations. Similar results were obtained with two additional experiments. ${ }^{*} P<0 \cdot 0005$, compared with the value of vehicle. $* * P<0 \cdot 0005$, compared with the value of FGF-2 with control siRNA transfection. phosphoinositide and phospholipase D-induced phosphatidylcholine in osteoblast-like MC3T3-E1 cells, and the protein kinase $\mathrm{C}$ activation plays an inhibitory role in the FGF-2stimulated IL-6 synthesis. In order to investigate whether protein kinase $\mathrm{C}$ induces p70 S6 kinase activation in MC3T3E1 cells, we examined the effect of TPA, a direct activator of protein kinase C (Nishizuka 1991), on the phosphorylation of p70 S6 kinase. The stimulation of TPA time dependently induced the phosphorylation of p70 S6 kinase (Fig. 3). The effect of TPA was observed $10 \mathrm{~min}$ after the stimulation of FGF2 and the maximum effect was at $45 \mathrm{~min}$.

Effects of Go6976 or bisindolylmaleimide I on the TPA-induced phosphorylation of p70 S6 kinase in MC3T3-E1 cells

We examined the effect of Go6976, a potent inhibitor of protein kinase C (Martiny-Baron et al. 1993), on the TPAinduced phosphorylation of p70 S6 kinase in MC3T3-E1 cells. Go6976 markedly reduced the phosphorylation of p70 S6 kinase (Fig. 4A). The effect of Go6976 was dose dependent in the range between $0 \cdot 3$ and $3 \mu \mathrm{M}$. In addition, bisindolylmaleimide I $(30 \mu \mathrm{M})$, another inhibitor of protein kinase C (Toullec et al. 1991), almost completely suppressed the TPA-induced phosphorylation of p70 S6 kinase (Fig. 4B). The effect of bisindolylmaleimide I was dose dependent in the range between 3 and $30 \mu \mathrm{M}$.

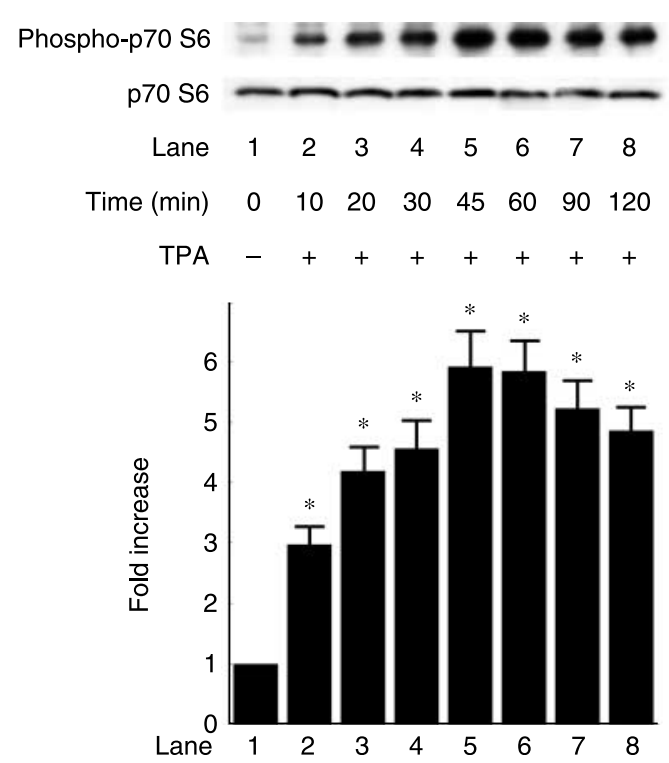

Figure 3 Effect of TPA on the phosphorylation of p70 S6 kinase in MC3T3-E1 cells. The cultured cells were stimulated by $0 \cdot 1 \mu \mathrm{M}$ TPA for the indicated periods. The extracts of cells were subjected to SDS-PAGE with subsequent western blot analysis with antibodies against phospho-specific p70 S6 kinase or p70 S6 kinase. The histogram shows quantitative representations of the levels of FGF-2-induced phosphorylation obtained from laser densitometric analysis of three independent experiments. Each value represents the mean \pm s.E.M. of triplicate determinations from three independent cell preparations. Similar results were obtained with two additional experiments. ${ }^{*} P<0 \cdot 0001$, compared with the value of control. 
Effects of Go6976, bisindolylmaleimide I, or calphostin C on the FGF-2-induced phosphorylation of $p 70$ S6 kinase in MC3T3E1 cells

We next examined the effects of protein kinase $\mathrm{C}$ inhibitors on the FGF-2-induced phosphorylation of p70 S6 kinase in MC3T3-E1 cells. The FGF-2-induced phosphorylation of

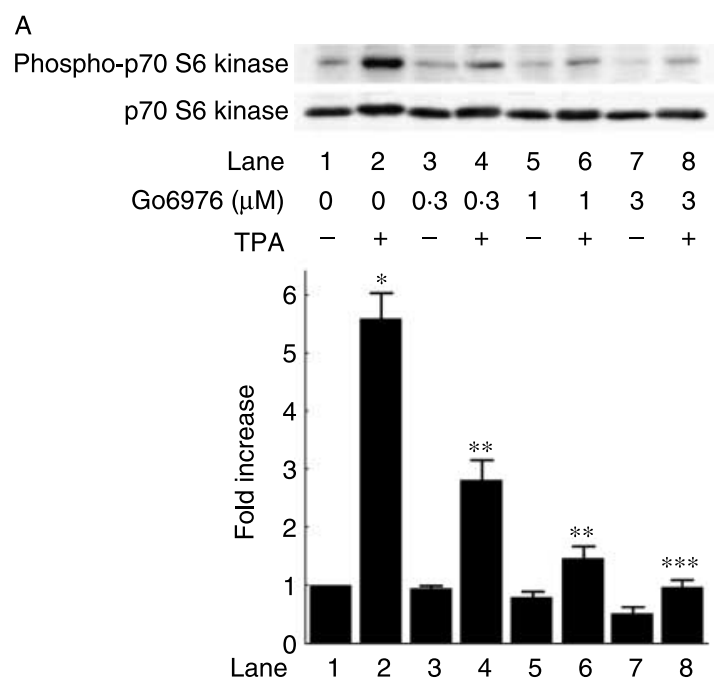

B
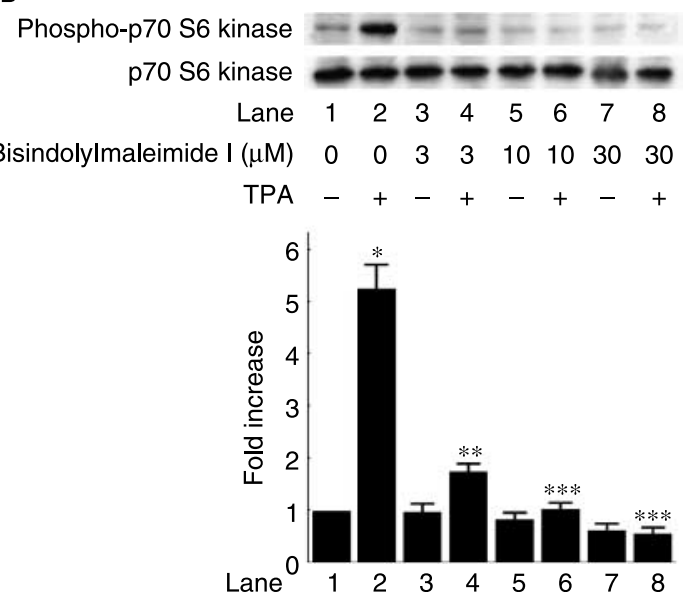

Figure 4 Effects of Go6976 or bisindolylmaleimide I on the TPAinduced phosphorylation of p70 S6 kinase in MC3T3-E1 cells. The cultured cells were pretreated with various doses of Go6976 (A) or $30 \mu \mathrm{M}$ bisindolylmaleimide I. (B) for $60 \mathrm{~min}$, and then stimulated by $0 \cdot 1 \mu \mathrm{M}$ TPA or vehicle for $20 \mathrm{~min}$. The extracts of cells were subjected to SDS-PAGE with subsequent western blot analysis with antibodies against phospho-specific p70 S6 kinase or p70 S6 kinase. ( $A$ and $B$ ) The histogram shows quantitative representations of the levels of FGF-2-induced phosphorylation obtained from laser densitometric analysis of three independent experiments. Each value represents the mean \pm s.E.M. of triplicate determinations from three independent cell preparations. Similar results were obtained with two additional experiments. ${ }^{*} P=0 \cdot 0001$, compared with the control. ${ }^{* *} P<0 \cdot 005$, compared with the value of TPA alone. $* * * P<0 \cdot 0005$, compared with the value of TPA alone. p70 S6 kinase was markedly attenuated by Go6976 or bisindolylmaleimide I (Fig. 5A and B). Furthermore, calphostin $\mathrm{C}$, an inhibitor of protein kinase $\mathrm{C}$ (Kobayashi et al. 1989), significantly suppressed the FGF-2-induced phosphorylation of p70 S6 kinase (Fig. 5C). Finally, we confirmed that the suppressive effects of these inhibitors were dose dependent.

\section{Discussion}

In our previous study, we showed that FGF-2 stimulated the IL-6 synthesis time dependently up to $48 \mathrm{~h}$, and the effect was dose dependent between 1 and $30 \mathrm{ng} / \mathrm{ml}$ (Kozawa et al. 1997a). In this study, we investigated whether p70 S6 kinase functions in the FGF-2-stimulated IL-6 synthesis or not in these cells. Rapamycin, a specific inhibitor of p70 S6 kinase (Kuo et al. 1992, Price et al. 1992), significantly amplified the FGF-2-stimulated synthesis of IL-6 in MC3T3-E1 cells. We found that rapamycin enhanced the FGF-2-stimulated IL-6 synthesis also in primary cultured mouse osteoblasts. These findings suggest that suppressive effect by p70 S6K on the FGF-2-stimulated IL-6 synthesis is not specific in a clonal osteoblast-like MC3T3-E1 cells but it is common in osteoblasts. We previously found that rapamycin strongly attenuated the FGF-2-induced phosphorylation of p70 S6 kinase (Takai et al. 2007b). In addition, the FGF-2-stimulated IL-6 synthesis was enhanced by downregulation of p70 S6 kinase by siRNA in MC3T3-E1. These results strongly suggest that FGF-2-activated p70 S6 kinase suppresses the FGF-2-stimulated IL-6 synthesis. Therefore, it is possible that p70 S6 kinase signaling activated by FGF-2 negatively regulates the FGF-2-induced over-synthesis of IL-6 in osteoblast-like MC3T3-E1 cells.

It is generally recognized that 1) the activity of p70 S6 kinase is regulated by multiple phosphorylation events (Pullen \& Thomas 1997) and 2) phosphorylation at Thr389 most strongly correlates with p70 S6 kinase activity among the phosphorylation sites (Pullen \& Thomas 1997). In the present study, we demonstrated that TPA time-dependently induced the phosphorylation of p70 S6 kinase at Thr389 in osteoblastlike MC3T3-E1 cells using phospho-specific p70 S6 kinase (Thr389) antibodies. In addition, the TPA-induced phosphorylation of p70 S6 kinase was markedly attenuated by Go6976, a potent inhibitor of protein kinase C. Furthermore, we found that bisindolylmaleimide I, another protein kinase C inhibitor, suppressed the p70 S6 kinase phosphorylation. Based on these results, it is most likely that p70 S6 kinase activation occurs via the activation of protein kinase $\mathrm{C}$ in osteoblast-like MC3T3-E1 cells.

We have previously reported that FGF-2 induces the activation of protein kinase $\mathrm{C}$ via phosphoinositide hydrolysis and phosphatidylcholine hydrolysis in osteoblast-like MC3T3-E1 cells, resulting in the negative regulation of the FGF-2-stimulated IL-6 synthesis (Suzuki et al. 1996, Kozawa et al. 1997a). Taken together, our findings led us to speculate 


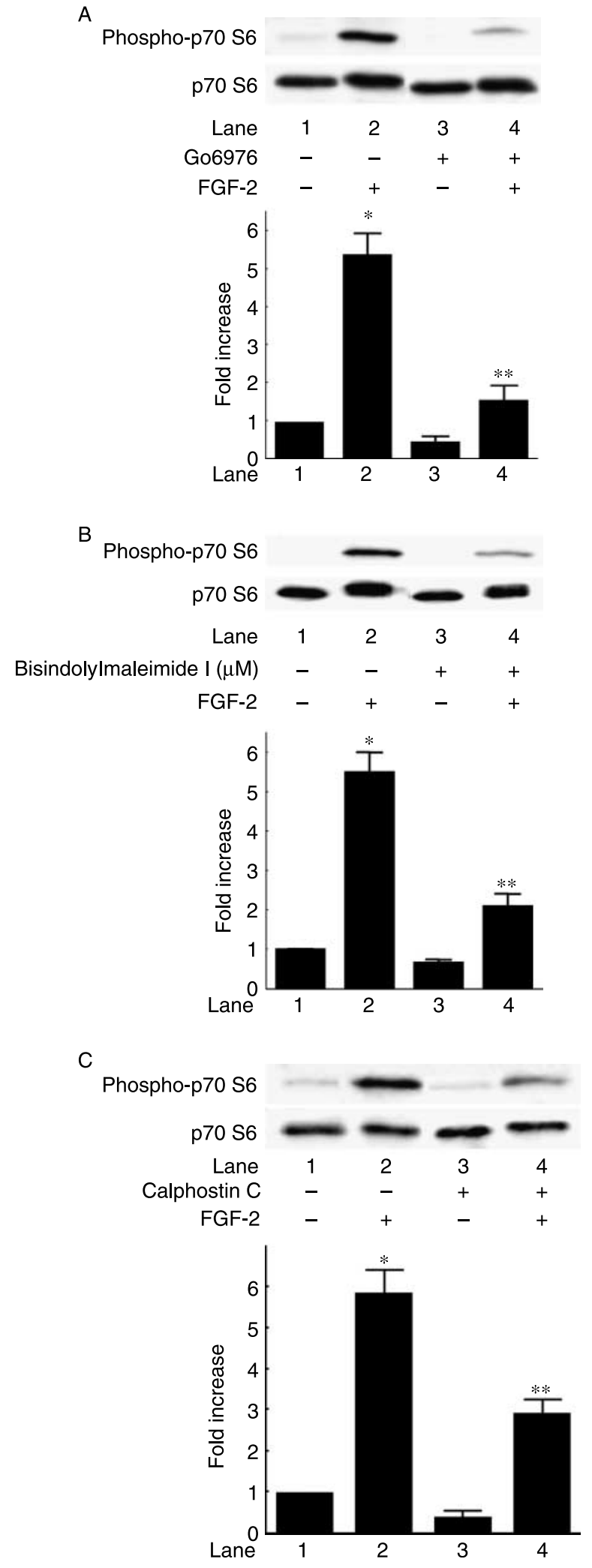

that protein kinase $\mathrm{C}$ functions at a point upstream from $\mathrm{p} 70$ S6 kinase in the FGF-2-regulated IL-6 synthesis in MC3T3E1 cells. We showed here that the phosphorylated levels of FGF-2-induced p70 S6 kinase were markedly reduced by Go6976 and bisindolylmaleimide I. In addition, we demonstrated that calphostin $\mathrm{C}$, another type inhibitor of protein kinase C, suppressed the FGF-2-induced phosphorylation of p70 S6 kinase. Taking our findings into account as a whole, it is probable that p70 S6 kinase acts as a negative regulator at a point downstream from protein kinase $\mathrm{C}$ in the FGF-2stimulated IL-6 synthesis in osteoblast-like MC3T3-E1 cells.

It is generally recognized that the p70 S6 kinase pathway plays an important role in various cellular functions, especially cell cycle progression (Pullen \& Thomas 1997). Based on our results, it is probable that the p70 S6 kinase pathway in osteoblasts has a pivotal role in the control of the production of IL-6, one of the key factors in bone remodeling. In our previous study (Takai et al. 2007a), we showed that p70 S6 kinase downregulates platelet-derived growth factorBB-stimulated IL-6 synthesis in osteoblast-like MC3T3-E1 cells. Since IL-6 is one of the most potent stimulators of osteoclast activity (Kwan et al. 2004), our results lead us to speculate that p70 S6 kinase signaling activated by growth factors such as FGF-2 and platelet-derived growth factor-BB in osteoblasts acts as a key regulator to suppress oversynthesizing IL-6, resulting in the prevention of excess bone resorption in the process of bone remodeling. Therefore, the p70 S6 kinase pathway in osteoblasts might be considered to be a new candidate as a molecular target of bone resorption concurrent with various bone diseases. On the other hand, we have recently reported that p70 S6 kinase acts as a negative regulator in the FGF-2-stimulated synthesis of VEGF factor in MC3T3-E1 cells (Takai et al. 2007b). It is well recognized that VEGF is angiogenic growth factor specific for vascular endothelial cells that provide microvasculature indispensable for bone remodeling (Erlebacher et al. 1995, Ferrara \& Davis-Smyth 1997). Taking our findings into account as a whole, p70 S6 kinase might play a central role in bone metabolism through the fine-tuning of the local factor network. Further investigation is required to clarify the exact role of p70 S6 kinase in bone metabolism.

Figure 5 Effects of Go6976, bisindolylmaleimide I, or calphostin $\mathrm{C}$ on the FGF-2-induced phosphorylation of p70 S6 kinase in MC3T3-E1 cells. The cultured cells were pretreated with $3 \mu \mathrm{M}$ G06976 (A), $30 \mu \mathrm{M}$ bisindolylmaleimide I (B), or $0 \cdot 7 \mu \mathrm{M}$ calphostin $\mathrm{C}(\mathrm{C})$ for $60 \mathrm{~min}$, and then stimulated by $0 \cdot 1 \mu \mathrm{M}$ TPA or vehicle for $20 \mathrm{~min}$. (A-C) The extracts of cells were subjected to SDS-PAGE with subsequent western blot analysis with antibodies against phospho-specific p70 S6 kinase or p70 S6 kinase. The histogram shows quantitative representations of the levels of FGF-2-induced phosphorylation obtained from laser densitometric analysis of three independent experiments. Each value represents the mean \pm S.E.M. of triplicate determinations from three independent cell preparations. Similar results were obtained with two additional experiments. ${ }^{*} P=0 \cdot 0001$, compared with the control. ${ }^{*} P<0 \cdot 005$, compared with the value of FGF-2 alone. 
In conclusion, our results strongly suggest that p70 S6 kinase functions at a point downstream of protein kinase $\mathrm{C}$ and limits FGF-2-stimulated IL-6 synthesis in osteoblasts.

\section{Acknowledgements}

We are very grateful to Yoko Kawamura and Seiko Sakakibara for their skillful technical assistance. This investigation was supported in part by Grant-in-Aid for Scientific Research (16590873 and 16591482) for the Ministry of Education, Science, Sports and Culture of Japan; the Research Grants for Longevity Sciences (15A-1 and 15C-2); the Research on Proteomics; and the Research on Longevity Sciences from the Ministry of Health, Labour and Welfare of Japan. The authors declare that there is no conflict of interest that would prejudice the impartiality of this scientific work.

\section{References}

Akira S, Taga T \& Kishimoto T 1993 Interleukin-6 in biology and medicine. Advances in Immunology $\mathbf{5 4}$ 1-78.

Baylink DJ, Finkleman RD \& Mohan S 1993 Growth factor to stimulate bone formation. Journal of Bone and Mineral Research 8 S565-S572.

Bolander ME 1992 Regulation of fracture repair by growth factors stimulate tyrosine kinase activity in vivo. Proceedings of the Society for Experimental Biology and Medicine 200 165-170.

Erlebacher A, Filvaroff EH, Gitelman SE \& Derynck R 1995 Toward a molecular understanding of skeletal development. Cell 80 371-378.

Ferrara N \& Davis-Smyth T 1997 The biology of vascular endothelial growth factor. Endocrine Reviews 18 4-25.

Helle M, Brakenhoff JPJ, DeGroot ER \& Aarden LA 1988 Interleukin-6 is involved in interleukin-1-induced activities. European Journal of Immunology 18 957-959.

Heymann D \& Rousselle AV 2000 gp130 Cytokine family and bone cells. Cytokine 12 1455-1468.

Hurley MM, Abreu C, Harrison JR, Lichtler AC, Raisz LG \& Kream BE 1993 Basic fibroblast growth factor inhibits type I collagen gene expression in osteoblastic MC3T3-E1 cells. Journal of Biological Chemistry 268 5588-5593.

Ishimi Y, Miyaura C, Jin CH, Akatsu T, Abe E, Nakamura Y, Yamaguchi Y, Yoshiki S, Matsuda T, Hirano T et al. 1990 IL-6 is produced by osteoblasts and induces bone resorption. Journal of Immunology $1453297-3303$.

Kato K, Ito H, Hasegawa K, Inaguma Y, Kozawa O \& Asano T 1996 Modulation of the stress-induced synthesis of hsp27 and alpha B-crystallin by cyclic AMP in C6 rat glioma cells. Journal of Neurochemistry 66 946-950.

Kobayashi E, Nakano H, Morimoto M \& Tamaoki T 1989 Calphostin C (UCN-1028C), a novel microbial compound, is a highly potent and specific inhibitor of protein kinase C. Biochemical and Biophysical Research Communications 159 548-553.

Kozawa O, Suzuki A \& Uematsu T 1997a Basic fibroblast growth factor induces interleukin-6 synthesis in osteoblasts: autoregulation by protein kinase C. Cellular Signalling 9 463-468.

Kozawa O, Suzuki A, Tokuda H \& Uematsu T $1997 b$ Prostaglandin $F_{2 \alpha}$ stimulates interleukin-6 via activation of PKC in osteoblast-like cells. American Journal of Physiology 272 E208-E211.

Kozawa O, Tokuda H, Matsuno H \& Uematsu T 1999 Involvement of p38 mitogen-activated protein kinase in basic fibroblast growth factor-induced interleukin-6 synthesis in osteoblasts. Journal of Cellular Biochemistry $\mathbf{7 4}$ $479-485$.
Kuo CJ, Chung J, Fiorentino DF, Flanagan WM, Blenis J \& Crabtree GR 1992 Rapamycin selectively inhibits interleukin-2 activation of p70 S6 kinase. Nature 358 70-73.

Kwan Tat S, Padrines M, Theoleyre S, Heymann D \& Fortun Y 2004 IL-6, RANKL, TNF-alpha/IL-1: interrelations in bone resorption pathophysiology. Cytokine and Growth Factor Reviews 15 49-60.

Laemmli LK 1970 Cleavage of structural proteins during the assembly of the head of bacteriophage T4. Nature 227 680-685.

Littlewood AJ, Russil J, Harvey GR, Hughes DE, Russel RGG \& Gowen M 1991 The modulation of the expression of IL-6 and its receptor in human osteoblasts in vitro. Endocrinology 129 1513-1520.

Marie PJ 2003 Fibroblast growth factor signaling controlling osteoblast differentiation. Gene 316 23-32.

Martiny-Baron G, Kazanietz MG, Mischak H, Blumberg PM, Kochs G, Hug H, Marm D \& Schachtele C 1993 Selective inhibition of protein kinase C isozymes by the indolocarbazole Go 6976. Journal of Biological Chemistry 268 9194-9197.

Nijweide PJ, Burger EH \& Feyen JHM 1986 Cells of bone: proliferation, differentiation, and hormonal regulation. Physiological Reviews 86 855-886.

Nishizuka Y 1991 Studies and perspectives of protein kinase C. Science 233 305-312.

Price DJ, Grove JR, Calvo V, Avruch J \& Bierer BE 1992 Rapamycin-induced inhibition of the 70-kilodalton S6 protein kinase. Science 257 973-977.

Pullen N \& Thomas G 1997 The modular phosphorylation and activation of p70s6k. FEBS Letters 410 78-82.

Roodman GD 1992 Interleukin-6: an osteotropic factor? Journal of Bone and Mineral Research 7 475-478.

Sudo H, Kodama H, Amagai Y, Yamamoto S \& Kasai S 1993 In vitro differentiation and calcification in a new clonal osteogenic cell line derived from newborn mouse calvaria. Journal of Cell Biology 96 191-198.

Susa M, Standke GJ, Jeschke M \& Rohner D 1997 Fluoroaluminate induces pertussis toxin-sensitive protein phosphorylation: differences in MC3T3-E1 osteoblastic and NIH3T3 fibroblastic cells. Biochemical and Biophysical Research Communications 235 680-684.

Suzuki A, Shinoda J, Kanda S, Oiso Y \& Kozawa O 1996 Basic fibroblast growth factor stimulates phosphatidylcholine-hydrolyzing phospholipase D in osteoblast-like cells. Journal of Cellular Biochemistry 63 491-499.

Takai S, Tokuda H, Hanai Y \& Kozawa O 2007a Limitation by p70 S6 kinase of PDGF-BB-induced IL-6 synthesis in osteoblast-like MC3T3-E1 cells. Metabolism 56 476-483.

Takai S, Tokuda H, Hanai Y, Harada A, Yasuda E, Matsushima-Nishiwaki R, Kato H, Ogura S, Ohta T \& Kozawa O 2007b Negative regulation by p70 S6 kinase of FGF-2-stimulated VEGF release through stress-activated protein kinase/c-Jun N-terminal kinase in osteoblasts. Journal of Bone and Mineral Research 22 337-346.

Toullec D, Pianetti P, Coste H, Bellevergue P, Grand-Perret T, Ajakane M, Baudet V, Boissin P, Boursier E, Loriolle F et al. 1991 The bisindolylmaleimide GF 109203X is a potent and selective inhibitor of protein kinase C. Journal of Biological Chemistry 266 15771-15781.

Yoshida M, Niwa M, Ishisaki A, Hirade K, Ito H, Shimizu K, Kato K \& Kozawa O 2004 Methotrexate enhances prostaglandin D2-stimulated heat shock protein 27 induction in osteoblast. Prostaglandins, Leukotrienes, and Essential Fatty Acids 71 351-362.

Received in final form 4 February 2008

Accepted 5 February 2008

Made available online as an Accepted Preprint 5 February 2008 